\section{Big Brother: telemorfose e criação de poeira ${ }^{1}$}

\section{RESUMO}

Este ensaio, do pensador francês Jean Baudrillard, analisa 0 fenômeno mundial de televisão chamado Big Brother. Para o autor, o programa sinaliza nosso ingresso numa "democracia radical".

\section{ABSTRACT}

In this essay Jean Baudrillard, the notorious French philosopher, analyses reality shows such as Big Brother and their phenomenal success as tv programs around the world. According to him, such programs indicate we are entering in an era of "radical democracy".

\section{PALAVRAS-CHAVE (KEY WORDS)}

- Televisão (Television)

- Imaginário (Imaginary)

- Reality shows
Jean Baudrillard

Sociólogo - França
Toda A NOSSA REALIDADE tornou-se experimental. Na ausência de destino, o homem moderno está entregue a uma experimentação sem limites sobre si mesmo.

Dois exemplos recentes disso são Big Brother, ilusão midiática do real ao vivo, e Catherine Millet, ilusão fantasmática do sexo ao vivo. ${ }^{2}$

Big Brother tornou-se um conceito universal, uma síntese de parque humano de atrações, de gueto, de quarto fechado e de Anjo Exterminador. A reclusão voluntária como laboratório de uma convivência sintética, de uma socialidade telegeneticamente modificada.

Quando tudo é mostrado (como no Big Brother e nos realitys shows), percebese que não há nada mais para se ver. É o espelho da superficialidade, do grau zero, por meio do qual se prova, em oposição a todos os objetivos, o desaparecimento do outro e talvez até que o ser humano não é essencialmente um ser social. Tem-se o equivalente de um ready-made - transposição literal do everyday life, ele próprio manipulado por todos os modelos dominantes. Banalidade sintética, fabricada em circuito fechado e com painel de controle.

Nisso, o microcosmo artificial do Big Brother parece-se com a Disneyland, que dá a ilusão de um mundo real, de um mundo externo, sendo que os dois correspondem exatamente à imagem um do outro. Os Estados Unidos inteiro são a Disneyland; todos nós estamos no Big Brother. Não é preciso entrar no duplo virtual da realidade, pois já estamos nele - o universal televisivo não passa de um detalhe holográfico da realidade global. Até em nossa existência mais cotidiana já estamos em situação de realidade experimental. É daí que vem o fascínio, por 
imersão e por interatividade espontânea.

Trata-se de voyeurismo pornô? Não. Há sexo por toda a parte, mas não é isso que as pessoas querem. Profundamente, desejam o espetáculo da banalidade, que é a verdadeira pornografia de hoje, a verdadeira obscenidade - a da mediocridade, da insignificância e da superficialidade. Extremo oposto do Teatro da Crueldade. Mas talvez haja aí uma forma de crueldade, ao menos, virtual. $\mathrm{Na}$ hora em que a televisão e a mídia são cada vez menos capazes de dar conta dos acontecimentos (insuportáveis) do mundo, elas descobrem a vida cotidiana, a banalidade existencial como o acontecimento mais mortífero, como a atualidade mais violenta, como o próprio local do crime perfeito. $E$, de fato, ela o é. As pessoas estão fascinadas, fascinadas e aterrorizadas pela indiferença do Nada a dizer, Nada a fazer; pela indiferença das suas próprias existências. A contemplação do Crime Perfeito, da banalidade como novo rosto da fatalidade, tornou-se uma verdadeira disciplina olímpica ou o último avatar dos esportes radicais.

Tudo isso reforçado com a mobilização do próprio público como juiz, pela sua transformação em Big Brother. Estamos além do panóptico, da visibilidade como fonte de poder e de controle. Não se trata mais de tornar as coisas visíveis a um olho exterior, mas de torná-las transparentes para elas mesmas, através de perfusão do controle na massa, apagando com isso os rastros da operação. Assim, os espectadores são envolvidos numa gigantesca contratransferência negativa sobre eles próprios e, mais uma vez, daí vem a atração vertiginosa desse gênero de espetáculo.

No fundo, tudo isso corresponde ao direito e ao desejo imprescritíveis de não ser Nada e de ser visto como tal. Há duas maneiras de desaparecer: ou se exige não ser visto (problemática atual do direito à imagem) ou se descamba para o exibicionismo delirante da própria mediocridade.

indivíduo faz-se medíocre para ser visto e contemplado como medíocre - última proteção contra a necessidade de existir e contra a obrigação de ser alguém.

Daí a exigência contraditória e simultânea de não ser visto e estar permanentemente visível. Todo o mundo atua, ao mesmo tempo, em dois campos e nenhuma ética nem legislação pode resolver os dilemas do direito incondicional de ver e de não ser visto. O máximo de informação faz parte dos direitos do homem; logo a visibilidade forçada também, a superexposição às luzes da informação.

A expressão de si como última forma de confissão, da qual falava Foucault, está aí. Não se deve guardar nenhum segredo. Falar, falar, comunicar incansavelmente. Tal é a violência praticada contra o ser singular e contra o seu mistério. É, ao mesmo tempo, uma violência contra a linguagem, pois esta, a partir disso, também perde a originalidade, não sendo mais do que médium, operador da visibilidade, perdendo toda a dimensão irônica ou simbólica - que torna a linguagem mais importante do que sobre o que se fala.

Pior, nessa obscenidade, nesse impudor, é a partilha forçada, essa cumplicidade automática do espectador, efeito de uma verdadeira chantagem. Este é o objetivo mais claro da operação: o servilismo das vítimas, mas a servidão voluntária das vítimas que gozam com o mal que lhes é feito, com a vergonha que Ihes é imposta. Toda uma sociedade partilha um mecanismo fundamental: a exclusão interativa - é o cúmulo! -, decidida em comum, consumida com entusiasmo.

Se tudo termina na visibilidade, a forma - como o calor na teoria da energia - mais degradada da existência, o ponto crucial, entretanto, é conseguir fazer dessa parte do todo um espaço simbólico, e dessa parte de desencantamento da vida um objeto de contemplação, de estupefação e de desejo perverso. "A humanidade que, outrora, com Homero, fora objeto de 
contemplação pelos deuses do Olimpo, o é agora para si mesma. A alienação de si mesma atingiu um grau que lhe faz viver a sua própria destruição como uma sensação estética de primeira ordem". (Walter Benjamin)

O experimental toma, assim, por toda a parte o lugar do real e do imaginário. Por tudo, os protocolos da ciência e da verificação são-nos inoculados; estamos dissecando, em vivissecção, sob o escalpelo da câmara, a dimensão relacional e social, fora de qualquer linguagem e contexto simbólico. Catherine Millet também é experimental - outro tipo de vivisexão: todo o imaginário da sexualidade é varrido, só restando um protocolo em forma de verificação ilimitada do funcionamento sexual, um mecanismo que, no fundo, nada mais tem de sexual.

Duplo contra-senso:

- Fazer da própria sexualidade a referência última. Recalcada ou manifesta, a sexualidade não é mais do que uma hipótese e, como tal, é falso fazer dela uma verdade e uma referência. A hipótese sexual só pode ser uma fantasia e, de qualquer maneira, foi no recalcamento que a sexualidade obteve essa aura de atrator estranho; manifesta, perde até mesmo essa qualidade potencial.

- Daí o contra-senso e o absurdo da passagem ao ato e de uma "liberação" sistemática do sexo: não se libera uma hipótese. Quanto a fazer a prova do sexo pelo sexo, que tristeza! Como se tudo não estivesse no movimento, no desvio, na transferência, na metáfora - tudo está no filtro da sedução, no desvio, não no sexo e no desejo, mas no jogo com o sexo e com o desejo. É isso que torna impossível a operação do sexo "ao vivo", assim como da morte ao vivo ou do acontecimento ao vivo no noticiário - tudo isso é incrivelmente naturalista; pretensão de fazer tudo advir ao mundo real, de tudo precipitar numa realidade integral. De algum modo, isso é a própria essência do poder. "A corrupção do poder consiste em fixar no real tudo que era da ordem do sonho..."

A chave é dada por Jacques Henric na sua concepção da imagem e da fotografia: inútil esconder o rosto, nossa curiosidade em relação às imagens é sempre de ordem sexual - tudo que aí buscamos é, enfim, o sexo, especialmente o sexo feminino. Não é somente a Origem do Mundo (Courbet), mas a origem de todas as imagens. Portanto, vamos a ele sem desvios; fotografemos só isso, obedeçamos, sem entraves, à nossa pulsão scópica. Esse é o princípio de uma "realerotik", da qual o acting-out copulativo perpétuo de Catherine Millet é o equivalente para o corpo; dado que, no final das contas, todo o mundo sonha com o uso sexual ilimitado do corpo, passemos, sem delongas, à execução do programa.

Nada mais de sedução, nada mais de desejo, nada mais até mesmo de gozo, tudo está aí, numa acumulação em que a quantidade desconfia, acima de tudo, da qualidade. Sedução perdida por decurso de prazo. A única questão a ser posta é a que se murmura no ouvido de uma mulher durante uma orgia: "What are you doing after the orgy?" Mas é inútil pois para ela não existe um além da orgia. Está, em realidade, além do fim, onde todos os processos tomam uma dimensão exponencial e só podem duplicar-se indefinidamente.

Assim, para Jarry, no Supermacho, uma vez atingido o limite crítico no sexo, pode-se praticá-lo indefinidamente; é o estágio automático da máquina sexual. Quando o sexo não passa de um sexprocessing, torna-se transposto e exponencial. Não atinge, porém, o seu objetivo, que seria de esgotar o sexo, de ir ao cabo do seu exercício. É evidentemente impossível. Essa impossibilidade é tudo o que resta de uma vingança da sedução, ou da própria sexualidade, contra os seus operadores sem escrúpulos - sem escrúpulos por eles mesmos, pelo próprio desejo e pelo próprio prazer deles.

"Pensar como uma mulher tira 
o vestido", diz Bataille. Sim, mas a ingenuidade de todas as Catherine Millet está em pensar que se tira o vestido para despir-se, para ficar nua e assim ter acesso à verdade nua do sexo ou do mundo. Se alguém tira o vestido é para aparecer - não aparecer nua como a verdade (quem pode acreditar que a verdade continua a ser verdade quando o seu véu é retirado?), mas para nascer no reino das aparências, ou seja, da sedução - o que é justamente o oposto.

Contra-senso total dessa visão moderna e desencantada que considera o corpo como um objeto que só espera ser desvestido e o sexo como um desejo que só espera passar ao ato e gozar. Ora, todas as culturas da máscara, do véu e do ornamento indicam exatamente o contrário: o corpo é uma metáfora e o verdadeiro objeto do desejo e do gozo são os signos, as marcas que o arrancam da sua nudez, da sua naturalidade, da sua "verdade", da realidade integral de seu ser físico. Por toda a parte, é a sedução que arranca as coisas da verdade delas (inclusive da verdade sexual). Se a reflexão tira o vestido, não é para se mostrar nua nem para desvelar o segredo do que, até então, estaria escondido, mas para mostrar esse corpo como definitivamente enigmático, secreto, como objeto puro, cujo segredo nunca será revelado nem pode ser.

Nessas condições, a mulher afegã de burka, a mulher de olhos cobertos por uma tela, na capa de Elle, apresentase como uma figura alternativa brilhante à virgem louca de Catherine Millet. $O$ excesso de segredo contra o excesso de impudor. De resto, esse impudor mesmo, essa obscenidade radical (como a de Big Brother), ainda é um véu, o último dos véus - inultrapassável, o que se interpõe quando pensamos tê-los rasgados todos. Pretendíamos ter chegado ao pior, ao paroxismo da exibição, ao desnudamento total, à realidade absoluta, ao direto e ao esfolado ao vivo - nunca se chega lá. Nada a fazer - o muro do obsceno é intransponível. Paradoxalmente essa busca perdida faz ainda mais ressurgir a questão fundamental do sublime, do segredo, da sedução, a mesma que se persegue até a morte na sucessão de véus rasgados.

Por que não adotar a hipótese, inversa à do voyeurismo e da estupidez coletiva, de que as pessoas - nós todos - buscam, chocando-se com o muro do obsceno, pressentir que, justamente, não há nada para ver? Como não se conhecerá jamais a última palavra, haveria assim uma verificação, a contrario, do derradeiro poder da sedução? Verificação desesperada, mas o experimental é sempre desesperado. Big Brother pretende demonstrar que o ser humano é um ser social - mas isso não é garantido. Catherine Millet pretende verificar, com suas experimentações, as próprias condições da experimentação, levadas simplesmente ao limite. O sistema decodifica-se melhor pelas suas extravagâncias, mas é o mesmo por toda a parte. A crueldade é a mesma por toda a parte. Tudo isso se resume, finalmente, para retomar Duchamp, a uma "criação de poeira".

\section{Telemorfose}

Big Brother tem três problemas: há o que acontece na casa, totalmente sem interesse; em contradição com essa insignificância, há o imenso fascínio que ela exerce. Mas esse próprio fascínio é objeto de fascinação pelo olhar crítico. Em tudo isso, onde está o acontecimento original? Não há. Só resta esse misterioso contágio, essa cadeia viral que funciona de uma ponta a outra, da qual somos cúmplices na análise. Inútil invocar todos os tipos de dados econômicos, políticos, publicitários - o mercado é o mercado e os próprios comentários fazem todos parte do mercado cultural e ideológico. O efeito de massa está além da manipulação e não se mede pelas causas. Isso o torna fascinante, como tudo o que resiste à inteligência. 
Primeira hipótese: se a audiência é tal, não é apesar da debilidade, mas graças à debilidade e à mediocridade do espetáculo. Isso parece indiscutível. Mas aqui se abrem duas possibilidades, talvez não excludentes. Ou os espectadores mergulham na nulidade do espetáculo e gozam com essa imagem, lipoaspirada para a circunstância, ou então eles gozam por sentir-se menos idiotas que o espetáculo - e por isso nunca se cansam de olhá-lo. Talvez seja, de fato, uma estratégia da mídia: oferecer espetáculos cada vez mais medíocres que a realidade - hiper-reais na debilidade -, dando aos espectadores uma possibilidade diferencial de satisfação. Hipótese sedutora, mas que supõe muita imaginação de parte dos programadores.

Devemos, portanto, ficar com a presunção de mediocridade - como se diz presunção de inocência. É isso a democracia radical. O princípio democrático era da ordem do mérito e de uma equivalência (certo, relativa) entre 0 mérito e o reconhecimento. Aqui, no Big Brother, nenhuma equivalência entre 0 mérito e a glória. É tudo em troca de nada. Princípio de inequivalência total. A ilusão democrática é, então, elevada ao mais alto grau: uma exaltação máxima por uma qualificação mínima. Enquanto o princípio tradicional só garantia ao mérito um reconhecimento parcial, a operação do Big Brother assegura a todos uma glória virtual justamente em função da falta de mérito. Num sentido, é o fim da democracia, por extinção de qualquer critério de qualificação, mas, por outro lado, é a concretização de uma democracia radical, com base na beatificação do homem sem qualidade. De fato, um grande passo rumo ao niilismo democrático.

Há nesse desequilíbrio entre o mérito e o reconhecimento público uma espécie de ruptura do contrato social que leva a outro tipo de injustiça e de anomalia; enquanto se podia acusar a democracia tradicional de não recompensar os cidadãos pelos seus justos méritos, aqui se deveria, de preferência, acusá-la de superestimar todos, indiferentemente, com base em nada.

Essa glória insólita atribuída a qualquer um teria, no limite, alguma coisa de engraçado e de uma ironia feroz - pois essa forma de democracia radical é uma derrisão em relação a tudo, establishment, políticos, intelligentsia ou star-system, a todos com pretensão a uma glória qualquer com base no status e no valor. Ao menos essa concorrência desleal dos start-up da glória revela a impostura latente de todos os sistemas de distinção, ao mesmo tempo que o absurdo de uma democracia embarcada na lógica do pior.

Dito isso, se essas novas vedetes, emocionantes pela insignificância e pela transparência, se essas usurpadoras, produtos de uma especulação desenfreada baseada na igualdade total, se esses piratas do hit parade não merecem esse excesso de glória, a sociedade que se oferece o espetáculo entusiasta dessa palhaçada faz bem por merecer o que tem. Big Brother é, ao mesmo tempo, o espelho e o desastre de uma sociedade inteira atolada na corrida ao insignificante e pasma diante da sua própria banalidade.

A televisão realizou com isso uma operação fantástica de consenso dirigido, um verdadeiro golpe de força, uma OPA sobre a sociedade inteira, uma tomada de reféns - formidável êxito rumo a uma telemorfose total da sociedade. Criou-se o acontecimento (ou, melhor, um nãoacontecimento) global e todo o mundo caiu na armadilha. "Um fato social total", como diz Marcel Mauss - salvo que, em outras culturas, isso significava o poder convergente de todos os elementos do social, enquanto aqui isso significa a elevação de uma sociedade inteira ao estágio de paródia de uma farsa total, de um implacável retorno de imagem sobre a própria realidade. A televisão fez o que nem a crítica mais radical nem a imaginação subversiva mais delirante e nenhuma derrisão situacionista conseguiram fazer. 
A televisão revelou-se mais forte na ciência das soluções imaginárias. Mas se a televisão o fez, nós o quisemos. Inútil acusar os poderes da mídia, o poder do dinheiro, até mesmo a estupidez do público para deixar crer que haveria uma alternativa racional a essa socialização integral, técnica e experimental, na qual estamos engajados, que resulta no encadeamento automático dos indivíduos em processos consensuais inexoráveis. Chamemos isso de acontecimento integral de uma sociedade, doravante, sem contrato, sem regras nem outro sistema de valores além de uma cumplicidade reflexa, sem regra nem lógica afora a do contágio imediato, de uma promiscuidade que nos mistura uns com os outros num imenso ser indivisível.

Tornamo-nos seres individualizados, ou seja, indivisíveis em si mesmos e entre eles. Essa individuação, da qual nos orgulhamos tanto, nada tem de uma liberdade pessoal, mas, ao contrário, é o signo de uma promiscuidade geral. Não necessariamente a dos corpos no espaço - certamente a das telas de uma ponta a outra do mundo. A verdadeira promiscuidade, sem dúvida, é da indivisibilidade de todas as partículas humanas a dezenas de milhares de quilômetros - como milhões de gêmeos que não chegam a separar-se do duplo. $O$ umbigo dos limbos.

Talvez seja também a de toda uma população com os figurantes do Big Brother. Ou, ainda, do casal "interativo" que projeta continuamente e em tempo real sua vida conjugal na Internet. Quem os olha? Eles se olham, mas quem mais, dado que cada um pode, virtualmente, gozar do mesmo circuito doméstico integrado? Não haverá, assim, em breve, mais do que zumbis autocomunicantes, tendo como único retransmissor umbilical a imagem refletida avatares eletrônicos das sombras defuntas que, além do Styx e da morte, erram, cada um por si, e passam o tempo a contar-se eternamente a própria história. Ainda há movimento, mas apenas o suficiente para dar, além do fim, a ilusão retrospectiva da realidade - ou a ilusão da sexualidade no caso de Catherine Millet - ou a ilusão do social, mas somente evocada em interação desesperada consigo mesma.

Um dos sinais dessa promiscuidade é a compulsão de reclusão que floresce por toda a parte - seja o recinto fechado da casa de Big Brother ou uma ilha, um gueto de luxo ou de lazer ou qualquer espaço fechado onde se possa recriar como que um nicho experimental ou uma zona privilegiada -, equivalente de um espaço de iniciação onde estejam abolidas as leis da sociedade aberta. Não se trata tanto de defender um território simbólico quanto de se fechar com a própria imagem, de viver em promiscuidade com ela, como num nicho, em cumplicidade incestuosa com ela, com todos os efeitos de transparência e de reflexo próprios à tela total, só tendo com os outros relações de imagem a imagem.

De resto, Big Brother também poderia ter sido fabricado com imagens de síntese - e o será algum dia. Mas, no fundo, já são imagens de síntese. Os gestos, os discursos e os atores já possuem todas as condições de pré-fabricação, de figuração programada, assim como se clonará biologicamente os seres humanos no futuro; mas, no fundo, eles já têm, cultural e mentalmente, um perfil de clones.

Essa promiscuidade, feita de involução mental, de implosão social, mas também de interação on-line, essa desautorização de qualquer dimensão de conflito, seria uma conseqüência acidental da evolução moderna das sociedade ou uma condição natural do homem que, finalmente, não pára de negar o seu ser social numa dimensão artificial? O ser humano é um ser social? Seria interessante ver o que acontecerá no futuro com um ser sem estrutura social profunda, sem sistema ordenado de relações e de valores - na pura contigüidade e promiscuidade das redes, em pilotagem automática e, de qualquer forma, num coma profundo -, contrariando assim todos os pressupostos 
antropológicos. Mas não temos, justamente, do homem uma concepção demasiado antropológica?

De qualquer maneira, visto o sucesso de Big Brother e a adesão entusiástica a essa encenação da servidão experimental, pode-se adivinhar que o exercício da liberdade não é certamente um dado fundamental da antropologia; se o homem alguma vez a praticou, não pára de abrir mão dela em favor de técnicas de automatismo coletivo mais animais. "Se o homem suporta mal a liberdade dos outros, é por ela não estar em conformidade com a natureza dele, não a suportando mais nem para si mesmo" (Dostoievski). Mas tem algo mais, pois à servidão, ele acrescentou o deleite do espetáculo da servidão.

Para dizer a verdade, o programa rapidamente se transformou numa telenovela, parecido com os shows de auditório de grande audiência. No caso, a audiência aumentou de acordo com o esquema habitual da mídia, pela concorrência dos veículos, o que leva o programa a difundir-se por si mesmo, de modo profético - self-fulfilling profhecy. No limite, o ibope é uma fraude, ele mesmo fazendo parte da espiral e do efeito bumerangue publicitário. Mas nada disso interessa. Vale somente a idéia original de submeter um grupo a uma experiência de isolamento sensorial ${ }^{3}$, a fim de registrar o comportamento das moléculas humanas no vácuo - e, sem dúvida, pelo desejo de vê-los devorar-se na promiscuidade artificial. Não chegamos a isso, mas essa microssituação existencial vale como metáfora universal do ser moderno fechado num loft pessoal, que não é mais o seu universo físico e mental, mas o seu universo tátil e digital, o do "corpo espectral" de Turing, do homem digital preso no dédalo das redes, do homem que se tornou o seu próprio mouse (branco).

A façanha consiste em entregar ao olhar da massa essa situação insuportável, fazendo-a saborear as peripécias numa orgia sem futuro. Grande façanha, que não acaba aí. Em breve, surgirão, numa seqüência lógica, os snuff movies e os suplícios corporais pela televisão. A morte deve logicamente entrar em cena como peripécia experimental. Não como sacrifício - no mesmo instante em que tentamos, tecnicamente, eliminá-la, ela reaparecerá nas telas como experiência radical (revival previsto, por certos grupos, da guerra de trincheiras ou dos combates do Pacífico sempre Disneyland, mas de um infantilismo um pouco mais cruel.

Mas, ao mesmo tempo, como pseudo-acontecimento, - essa é a ironia de todas essas palhaçadas experimentais -, em paralelo à multiplicação desses espetáculos de violência cresce a incerteza quanto à realidade do que é mostrado. É verdade ou não? Quanto mais se avança na orgia da imagem e do olhar, menos se pode acreditar. A visão em "tempo real" só aumenta a irrealidade da coisa. Os dois paroxismos, da violência da imagem e do descrédito da imagem, crescem segundo a mesma função exponencial. Por causa disso, estamos sempre fadados à decepção (cada vez mais com as imagens de síntese), mas relançados por essa mesma decepção. Pois essa incerteza profunda (estratégica, política - em benefício de quem?) está, em grande parte, na demanda insaciável desse gênero de espetáculo.

Curiosidade vertiginosa que poderia ser confundida com voyeurismo, mas que, de fato, nos casos do Big Brother e de Catherine Millet, não tem muito de sexual. É uma curiosidade de ordem visceral, orgânica, endoscópica. Evoca o strip-tease japonês em que os clientes são convidados a mergulhar o nariz e os olhos na vagina de uma mulher, para explorar, parece, o segredo das suas entranhas - tão fascinante quanto a penetração sexual. Gozo espeleológico (não longe da videoscopia do interior do corpo por microcâmeras), abertura escancarada sobre o abismo do corpo inteiro. Isso também não está longe da história do califa que, depois do strip-tease da bailarina, manda esfolá-la 
viva, sempre para ver mais.

O sexo e o saber do sexo são superficiais em relação a isso. A verdadeira curiosidade abissal é a do foro interior. Essa abertura compulsiva, fetal, involutiva, que me parece estar em jogo na atividade "sexual" de Catherine Millet e no fascínio exercido por ela. Será possível uma penetração mais profunda, mais profunda mesmo do que a sexual? Podemos possuir e ser possuídos a fundo?

Trata-se, evidentemente, de uma aventura sem saída que só pode acaba na repetição incontável de um ato sexual incapaz de levar ao conhecimento absoluto do corpo nem ao gozo mortal pelo seu esgotamento. No Supermacho de Jarry, em que Ellen e Marcueil também flertam com o limite das energias sexuais, Ellen morre (momentaneamente) ao término dessa proeza. Nada parecido com Catherine Millet, cuja aventura está mais para anorexia sexual contrariada. Interessante é que, levando o sexo ao absurdo, até a serialidade em que só se define pelo automatismo (como os cadáveres velocípedes de Jarry que pedalam melhor quando estão mortos), arrancando o sexo ao princípio mesmo do prazer, ela o arranca também do seu princípio de realidade e obriga, aí também, a perguntar: que é feito do ser sexual?

Não seria a sexualidade, contrariamente à evidência natural, somente uma hipótese? Verificada, como aqui, até o esgotamento, deixa-nos dubitativos. Verificada além do seu fim, não sabe simplesmente mais o que é... Tudo isso é para ser revisto: com Big Brother, a evidência do ser humano como ser social; com Catherine Millet, a evidência do ser humano como ser sexual; com o excesso de transparência e de informação, a evidência da própria realidade.

Sexuados, certo, nós somos - e Catherine Millet também -, mas sexuais? É outra questão.

Socializados, nós somos (com freqüência, pela força), mas seres sociais?
Resta ver.

Realizados, sim - mas reais? Nada menos seguro.

Catherine Millet tem em comum com as pessoas do Big Brother o fato de submeter-se, por escolha própria, a do serial fucking, ao mesmo isolamento sensorial - dando lugar à mesma atividade minimalista, radical, exclusiva, que, pela sua própria repetição, torna-se virtual. Não apenas ela se livra de toda troca dual e toda partilha sexual, mas também de qualquer obrigação de escolher - e, no fundo, também do seu próprio corpo. Pode-se ver nessa recusa da escolha, assim como de qualquer afinidade eletiva, uma espécie de ascese, de despojamento da vontade (que é só, como se sabe, uma ilusão subjetiva) capaz de quase transformar Catherine Millet, como disseram alguns, numa santa...

Mas onde está a sexualidade? Esta é, sem dúvida, uma hipótese menos ilusória que a da verdade, mas é bom pôr-lhe um fim, verificando-a com obsessão. Se acabar com o desejo e com o seu conceito pode ser caracterizado como um niilismo da vontade, então essa prova reiterada da existência do sexo pelo sexo pode ser considerada como niilismo sexual. A menos que...

A menos que o objetivo secreto seja de livrar-se do próprio sexo? Esgotar essa função mecânica dos corpos antes de passar ao grande jogo... Esse é, claro, o subentendido de WHAT ARE YOU DOING AFTER THE ORGY? Paga a aposta e realizada a performance (we did it!), não se poderia passar às coisas sérias e sentir realmente prazer? Assim, o verdadeiro gastrônomo, segundo Noëlle Châtelet, trata, primeiro, de alimentar-se, de nutrir-se, antes de passar aos prazeres da mesa, que a fome não deve perturbar.

Ellen, depois do rallye sexual com Marcueil: "Isso não foi nem um pouco divertido". Marcueil, aliás, compara a ereção tetânica e a disposição paralela na mulher a uma "esclerose" ou a uma crispação espasmódica dos tecidos. Ellen, 
logo, convida-o, em segredo, a recomeçar, mas dessa vez justo "pelo prazer" (e sem o olhar do cientista Bathybius, que registrava cientificamente a proeza).

Se essa reviravolta não acontece, o que há depois da orgia? Nada, a não ser, em Jarry, esse personagem do Amor Absoluto, Sengle, que, em plena atividade erótica, conta as estocadas e, percebendo ter errado na contagem, exclama: "Bom, a gente apaga tudo e recomeça".

Catherine Millet experimenta o mesmo isolamento sensorial de Big Brother; há a mesma abertura atrativa no espetáculo do Big Brother que na oferenda sexual de Catherine Millet. Mesma curiosidade vaginal, mais que vaginal, uterina, pelo buraco do Big Brother, desta vez aberta para outro abismo, o do vazio e da insignificância. Ir sempre mais fundo rumo a essa verdadeira cena primitiva da modernidade. Onde está o segredo da banalidade, dessa nulidade superexposta, iluminada, informada por todos os lados e que não deixa ver mais nada de tanta transparência? O verdadeiro mistério torna-se o da confissão forçada da vida como ela é... Objeto, ao mesmo tempo, de pavor intenso e da tentação vertiginosa de mergulhar nos seus limbos - os limbos de uma existência no vácuo e sem nenhum significado: o próprio espetáculo que nos é oferecido pelo Big Brother e pelos seus atores.

O século $X X$ viu todos os tipos de crime - Auschwitz, Hiroshima, genocídios -, mas o único verdadeiro crime perfeito é, conforme os termos de Heidegger, "a segunda queda do homem, a queda na banalidade".

Violência assassina da banalidade que, justamente na sua indiferença e na sua monotonia, é a forma mais sutil de exterminação. Um verdadeiro teatro da crueldade, da nossa crueldade, completamente desdramatizada e sem rastro de sangue. Crime perfeito por abolir qualquer móbil e apagar todos os indícios - mas sobretudo por, nesse crime, sermos, ao mesmo tempo, assassinos e vítimas. Enquanto essa distinção existe, o crime não é perfeito. Ora, em todos os crimes históricos que conhecemos a distinção é clara. Só no suicídio o matador e a vítima se confundem. Nesse sentido, a imersão na banalidade é bem o equivalente de um suicídio da espécie.

O outro aspecto dessa banalidade assassina é que ela apaga o teatro de operação do crime - ele está agora por toda a parte na vida, em todas as telas, na falta de distinção entre a vida e a tela. Aí também estamos, ao mesmo tempo, dos dois lados. Enquanto dos outros crimes nos é mostrada uma imagem ("Shoah", "Apocalypse now"), ao menos ela diferenciada, esta exterminação suave nos é mostrada sob a forma de um tipo de espetáculo: Big Brother e outros, dos quais fazemos parte.

Trata-se de uma verdadeira síndrome de Estocolmo em escala coletiva - quando o refém se torna cúmplice do seqüestrador -; logo, de uma revolução do conceito de servidão voluntária e da relação senhor/ escravo. A sociedade inteira torna-se cúmplice dos que a tomaram como refém, mas também cada indivíduo se divide, por si mesmo, em refém e seqüestrador.

Há uma longa história dessa promiscuidade crescente, desde a mitificação da vida cotidiana e de sua irrupção na dimensão histórica - até o processo implacável de imersão no real demasiado real, no humano demasiado humano, no banal e no residual. Mas a última década viu uma aceleração extraordinária dessa banalização do mundo, através da informação e da comunicação universal - e sobretudo pelo fato de que essa banalidade se tornou experimental. $\mathrm{O}$ campo da banalidade não é mais somente residual, mas se tornou um teatro de operações. Levada à tela, como em Big Brother, torna-se um objeto experimental de lazer e de desejo. Verificação do que McLuhan dizia da televisão: ela é um eterno teste e nós somos tratados como cobaias, 
numa interação mental automática.

Big Brother não é apenas um detalhe. É toda a "realidade" que passou de armas e bagagens para o outro lado, como no filme Truman Show, em que não apenas o protagonista é telemorfoseado, mas todos os outros também - cúmplices e prisioneiros em plena luz da mesma fraude. Houve um tempo - como no filme A Rosa Púrpura do Cairo - em que os personagens saíam da tela e encarnavam-se na vida real, numa inversão poética da situação. Hoje, é a realidade que se desencarna na tela. Nada mais as separa. A osmose - a telemorfose - é total.

Pleasantville, em sentido inverso, dava o exemplo heróico de um casal de jovens telespectadores que entra no programa e altera-Ihe a continuidade injetandolhe paixões humanas (curiosamente, de resto, não é o sexo que ressuscita a vida real e devolve a cor ao mundo em pretoe-branco - o segredo está noutro lugar). Mas tudo isso faz parte de um vaivém entre a tela e a realidade ultrapassado. A tela, hoje, não é mais a da televisão, mas a da própria realidade - disso que se chama de realidade integral. Catherine Millet faz parte da sexualidade integral. A imanência da banalidade, o mais real que o real, a realidade integral. A realidade é um processo em via de extinção, por absorção, no noticiário e no virtual, de toda dimensão fatal, pelo assassínio subjacente à pacificação da vida e ao consumo entusiástico dessa banalidade alucinógena. Retorno aos limbos, a essa zona crepuscular onde tudo chega ao fim pela própria realização.

Em alguma parte, estamos de luto por essa realidade nua, essa existência residual, essa desilusão total. Há, nessa história do Big Brother, alguma coisa de um luto coletivo, mas que faz parte da solidariedade que une os criminosos que somos todos - os assassinos desse crime perpetrado contra a vida real e de cuja confissão nos esvaziamos na tela, que, de qualquer forma, nos serve de confessionário (o confessionário é um dos lugares do Big Brother). Aí reside a nossa verdadeira corrupção, a corrupção mental, no consumo desse luto e dessa decepção, fonte de gozo contrariado. De qualquer maneira, entretanto, a desautorização dessa palhaçada experimental transparecia no tédio mortal que disseminava.

Dito isso, não há razão para o homem não reivindicar com força o seu direito à banalidade, ao insignificante e à mediocridade - tanto quanto ao oposto. $\mathrm{O}$ direito, de qualquer maneira, também faz parte da banalização da existência.

Socialidade integral - sexualidade integral - realidade integral: todo esse processo seria catastrófico se houvesse uma verdade do social, uma verdade do sexual, uma verdade do real. Felizmente só existem hipóteses. Mesmo se, hoje, elas assumem a forma de uma realidade monstruosa, continuam a ser apenas hipóteses. Para sempre inverificáveis - 0 segredo nunca será revelado. A verdade, se existisse, estaria no sexo. O sexo seria a palavra final desta história... Mas não há... Por isso, a sexualidade nunca passará de uma hipótese.

Significa que o perigo absoluto de uma ação sistemática do social, de uma prática sistemática do sexual e de uma operação sistemática do real não é mais que... virtual.

Daí a outra pergunta, como interrogação final: quem ria no Big Brother? Nesse mundo imaterial, sem um rastro de humor, que monstro poderia rir nos bastidores? Que divindade sarcástica poderia rir disso na intimidade? O humano demasiado humano deve ter-se revirado na tumba. Mas, como se sabe, as convulsões humanas servem para a distração dos deuses, que só podem rir .

\section{Notas}

1 Tradução de Juremir Machado da Silva. Texto cedido pelo autor. 
2 Big Brother foi intitulado na França Loft Story. Catherine Millet escreveu o best-seller La Vie sexuelle de Catherine M. (N.T.).

3 Que, em outros lugares, foi uma espécie de tortura calculada. Mas não estamos explorando todas as formas históricas de tortura, servidas em doses homeopáticas, como se fossem cultura de massa ou de vanguarda? É um dos temas principais da arte contemporânea. 